\title{
BioDrugs
}

\section{Optimisation of TNF-Inhibitor Therapy for Rheumatoid Arthritis: Focus on Certolizumab Pegol}

\author{
Guest Editor: \\ Daniel Aletaha \\ Division of Rheumatology, Medical University of Vienna, \\ Vienna, Austria \\ Peer Reviewer \\ Leonard H. Calabrese \\ College of Medicine of Case Western Reserve University, Cleveland, Ohio, US
}

Funding for medical writing assistance in preparation of this supplement was provided by an educational grant from UCB PHARMA s.p.a.

Conflicts of interest: This supplement was guest edited by Daniel Aletaha and peer reviewed by Leonard H. Calabrese who both received a small honorarium from Springer Healthcare to cover out-of-pocket expenses. D.A. has received honoraria and research grants from UCB, and honoraria from Abbvie, Grünenthal, Janssen, Merck,

Medac, Mitsubishi Tanabe, Pfizer, AstraZeneca, Eli Lilly, Novo Nordisk, and Sanofi/Regeneron. L.H.C. has consulted for UCB, Roche, Janssen, Pfizer and BMS. 